\title{
Serological Survey on the Occurrence of Rickettsia spp., Neospora caninum, Bartonella henselae and Toxoplasma gondii in Cats from Tuscany (Central Italy)
}

\author{
Valentina Virginia Ebani ${ }^{1,2, *}$, Simona Nardoni ${ }^{1}\left(\mathbb{D}\right.$, Michela Maestrini $^{1}\left(\mathbb{D}\right.$, Stefania Perrucci $^{1}(\mathbb{D})$ and \\ Francesca Mancianti ${ }^{1}$ (D) \\ 1 Department of Veterinary Sciences, University of Pisa, Viale delle Piagge 2, 56124 Pisa, Italy; \\ simona.nardoni@unipi.it (S.N.); michela.maestrini@phd.unipi.it (M.M.); stefania.perrucci@unipi.it (S.P.); \\ francesca.mancianti@unipi.it (F.M.) \\ 2 Centre for Climate Change Impact, University of Pisa, Via del Borghetto 80, 56124 Pisa, Italy \\ * Correspondence: valentina.virginia.ebani@unipi.it
}

check for updates

Citation: Ebani, V.V.; Nardoni, S.; Maestrini, M.; Perrucci, S.; Mancianti, F. Serological Survey on the Occurrence of Rickettsia spp., Neospora caninum, Bartonella henselae and Toxoplasma gondii in Cats from Tuscany (Central Italy). Animals 2021, 11, 1842. https://doi.org/ 10.3390/ani11061842

Academic Editor: Marsilio Fulvio

Received: 30 May 2021

Accepted: 18 June 2021

Published: 21 June 2021

Publisher's Note: MDPI stays neutral with regard to jurisdictional claims in published maps and institutional affiliations.

Copyright: (c) 2021 by the authors. Licensee MDPI, Basel, Switzerland. This article is an open access article distributed under the terms and conditions of the Creative Commons Attribution (CC BY) license (https:// creativecommons.org/licenses/by/ $4.0 /)$.
Simple Summary: Domestic and stray cats are frequently infected by pathogens, some of which are zoonotic. The occurrence of microorganisms such as Bartonella henselae and Toxoplasma gondii, even though they are well known, could be underestimated because they are not regularly investigated in cats. Other pathogens, such as Neospora caninum and Rickettsia spp., have not been largely studied in feline populations and data about their spreading in Italian cats are very scanty. Monitoring of domestic and stray cats for these pathogens is important to evaluate the health status of the animals, but also, regarding B. henselae, Rickettsia spp. and T. gondii, from a One Health perspective.

Abstract: Asymptomatic cats often harbor pathogens, some of which have not been largely investigated in feline populations. The aim of this study was to evaluate the occurrence of antibodies against Rickettsia conorii, Rickettsia felis, Rickettsia typhi, Neospora caninum, Bartonella henselae and Toxoplasma gondii in cats from Tuscany. Ninety-five blood serum samples, previously collected, were analyzed by indirect immunofluorescence assay. Fifty-six (58.94\%) cats had antibodies to at least one investigated pathogen: $28(29.47 \%)$ cats were positive for B. henselae, $17(17.89 \%)$ for R. felis, $14(14.73 \%)$ for R. conorii, 14 (14.73\%) for T. gondii, 2 (2.1\%) for N. caninum. No cats were positive for R. typhi. Positive reactions to two or more pathogens were detected in 18 (18.94\%) cats. The occurrence of antibodies against these microorganisms suggests that cats, even though asymptomatic, may be infected by pathogens, often zoonotic, and thus may be a source of infections for other animals and humans.

Keywords: cats; indirect immunofluorescence test; Neospora caninum; Rickettsia felis; Rickettsia conorii

\section{Introduction}

Domestic and stray cats (Felis catus), even though asymptomatic, may harbor different pathogens that can represent a relevant issue for the health status of animals and humans. Cats living outdoors have more occasions to contract microorganisms excreted by infected animals, as well as increased exposure to hematophagous arthropods that frequently act as vectors of different pathogens. Some infections, such as those caused by Bartonella henselae and Toxoplasma gondii, have been largely studied and the human clinical forms well described. On the other hand, some microorganisms can be considered as emerging pathogens and data about their circulation in feline populations, as well as the zoonotic potential for some of them, are scanty.

$B$. henselae belongs to the genus Bartonella which includes several species able to infect animals and humans. B. henselae is a facultative intracellular, hemotropic Gramnegative bacteria; it is usually transmitted by Ctenocephalides felis, whereas cats act as reservoirs [1]. This pathogen is the causative agent of cat scratch disease (CSD), which 
affects human beings, mainly children and immunocompromised patients, and is linked to conditions such as lymphadenopathy, bacteremia, Parinaud's oculoglandular syndrome, peliosis hepatis, endocarditis, neuroretinitis, meningitis, pneumonia, musculoskeletal manifestation; bacillary angiomatosis has been related to $B$. henselae infection, too [2].

Toxoplasma gondii is an Apicomplexan protozoon, infecting a wide range of animals, with a life cycle that involves cats as final hosts. Infected cats can excrete unsporulated T. gondii oocysts by feeding on infected prey, acting as definitive hosts, or may become infected by ingesting sporulated oocysts from the environment. Asexual multiplication occurs in a wide range of intermediate hosts, among which are human beings. Toxoplasmosis is a zoonotic disease, life threatening in immunodeficient human patients and in fetuses [3] and the most common causative agent of chorioretinitis [4] in immunocompetent people, too. Moreover, T. gondii can induce abortion and neonatal mortality in ruminants [5]. For these reasons this infection in cats remains a public health and veterinary concern [6].

Genus Rickettsia includes several species able to cause disease in animals and humans, classified in the spotted fever group (SFG) and typhus group (TG).

Among SFG species, $R$. conorii is the most known rickettsial agent in Europe, responsible for the disease called Mediterranean spotted fever. The brown dog tick Rhipicephalus sanguineus is the main vector but also the main reservoir since dogs can suffer the illness [7]. Other SFG Rickettsia spp. have been found in animals and arthropod specimens in Europe, including Italy [7].

$R$. felis is considered as an emerging SFG species which infects cats and humans. It is usually transmitted by C. felis fleas [8]. C. felis is considered the reservoir of R. felis, which is vertically transmitted to successive generations of fleas [9], whereas cats are not considered as reservoirs of this agent because it seems that they usually develop a shortterm bacteremia. $R$. felis causes human disease with common signs such as fever, headache, myalgia, cutaneous rash; furthermore respiratory, digestive and neurological symptoms have been reported [10].

$R$. typhi is a worldwide flea-borne TG rickettsial species. It is primarily transmitted by the rat flea Xenopsylla cheopis and rodents (mainly Rattus norvegicus and Rattus rattus) act as the main reservoirs. Cats and C. felis are involved in the epidemiology of this infection, too. R. typhi is the etiologic agent of the human disease murine typhus. Fever, headache, arthralgia and cutaneous rash are the common clinical signs in infected people, but severe disease with pneumonia and ophthalmic complications has been observed mainly in elderly and transplanted patients [11].

Neospora caninum is an Apicomplexan protozoon with a life cycle like T. gondii, but involving dogs as final hosts. N. caninum is responsible for abortion in bovine and in small ruminants and for neuromuscular disease in dogs. Cats are susceptible to experimental infection $[12,13]$ as several domestic and wild animal species are exposed to the parasite [14].

Data about the circulation of Rickettsia spp. and N. caninum in Italian feline populations are very scanty, thus the aim of the present study was to verify the occurrence of antibodies against $R$. felis, $R$. typhi, R. conorii and N. caninum in clinically healthy cats living outdoors in Tuscany (Central Italy). Furthermore, the serum samples were also submitted to serological tests for B. henselae and T. gondii.

\section{Material and Methods}

\subsection{Animals}

Ninety-five blood serum samples previously collected from cats were selected and used in this survey. The samples were collected from January 2018 to March 2021 from cats during routine clinical visits for FIV / FeLV screening by collaborating veterinarians. Owners' consent was obtained in all cases. Among the available serum samples, only those from cats with the following features were used in the present investigation: (1) FIV/FeLV negative, (2) clinically healthy, (3) living outdoors, (4) infested by fleas and/or ticks, (5) not under antibiotic treatment. 
The 95 selected animals were 35 females and 60 males; 47 were $\leq 12$ months old and $48>12$ months old.

\subsection{Serological Tests}

Indirect immunofluorescence assay (IFA) was carried out, following the manufacturers' instructions, to detect antibodies against the investigated antigens. The tests were executed using different commercial IFA slides coated with the following antigens: $B$. henselae, N. caninum, R. conorii, R. felis, R. typhi (Fuller Laboratories Fullerton, Fullerton, CA, USA) and T. gondii (Toxospot $\mathrm{IF}^{\circledR}$ Biomérieux, Lyon, France), respectively. A fluorescein isothiocyanate-conjugated sheep anti-cat IgG (Sigma-Aldrich, Saint Louis, MO, USA) diluted 1:50 in Evans Blue (Sigma-Aldrich, Saint Louis, MO, USA) solution was used.

All sera were tested at 1:32 dilution for $B$. henselae and rickettsiae and at 1:20 for T. gondii and N. caninum [15]. Positive samples were twofold serially diluted to determine the endpoint titer.

\subsection{Statistical Analysis}

Statistical evaluation was carried out by the $\chi^{2}$ test to analyze the results of serological tests in relation to gender and age. Values of $p<0.05$ were considered significant.

\section{Results}

The 95 tested cats were infested by C. felis fleas. Fifty-six (58.94\%) cats had antibodies to at least one investigated pathogen: $22 / 35$ (62.85\%) females and 29/60 (48.33\%) males; $27 / 47(57.44 \%)$ were $\leq 12$ months old and $24 / 48(50 \%)>12$ months old. The observed differences were not statistically significant.

Regarding the investigated pathogens, 28 (29.47\%) cats were positive for $B$. henselae ( $n=12$ titer $1: 64, n=9$ titer $1: 128, n=4$ titer 1:256, $n=3$ titer 1:512), 17 (17.89\%) for $R$. felis ( $n=7$ titer 1:32, $n=7$ titer 1:64, $n=3$ titer 1:128), 14 (14.73\%) for $R$. conorii $(n=11$ titer 1:32, $n=3$ titer 1:64), 14 (14.73\%) for T. gondii ( $n=1$ titer $1: 40, n=4$ titer 1:80, $n=6$ titer 1:160, $n=1$ titer 1:320, $n=2$ titer 1:2560), 2 (2.1\%) for $N$. caninum (titer 1:20). No cats were positive for R. typhi.

Positive reactions to two or more pathogens were detected in $18(18.94 \%)$ cats (Table 1$)$.

Table 1. Details of the cats testing positive to two or more pathogens.

\begin{tabular}{|c|c|c|c|c|c|}
\hline Cat ID & Bartonella henselae & Neospora caninum & Rickettsia conorii & Rickettsia felis & Toxoplasma gondii \\
\hline M11 & & & & $1: 32$ & $1: 2560$ \\
\hline M14 & $1: 64$ & & & & $1: 2560$ \\
\hline M26 & & & $1: 64$ & $1: 64$ & \\
\hline M23 & & & $1: 32$ & $1: 64$ & \\
\hline M27 & $1: 128$ & & & & $1: 160$ \\
\hline M28 & $1: 64$ & $1: 20$ & & $1: 128$ & \\
\hline M40 & $1: 256$ & & & $1: 64$ & \\
\hline M41 & & & $1: 32$ & $1: 128$ & \\
\hline M46 & & & $1: 32$ & & $1: 160$ \\
\hline M48 & $1: 64$ & $1: 20$ & & $1: 128$ & \\
\hline M54 & $1: 128$ & & & & $1: 320$ \\
\hline PI16 & $1: 64$ & & & $1: 32$ & \\
\hline PI24 & & & & $1: 32$ & $1: 80$ \\
\hline PI31 & $1: 64$ & & $1: 32$ & & \\
\hline PI45 & $1: 128$ & & & & $1: 40$ \\
\hline N50 & $1: 512$ & & $1: 32$ & $1: 32$ & \\
\hline N60 & $1: 512$ & & $1: 64$ & & \\
\hline N64 & $1: 128$ & & $1: 32$ & & \\
\hline
\end{tabular}




\section{Discussion}

The results obtained in the present study show that the selected feline population was exposed to most of the investigated pathogens. No statistically significant differences were observed in relation to age and gender.

A $29.47 \%$ prevalence of cats seropositive to $B$. henselae confirms this microorganism as one of the most widespread zoonotic agents in feline populations. Previous serological surveys found different percentages of positive cats, mainly in relation to the condition of the tested animals and the geographic areas where they lived. In Northern Italy, prevalences of $30 \%$ and $39 \%$ were detected in domestic and stray cats, respectively [16], whereas a later study found $23.1 \%$ of seropositive stray cats [17]. Recently, a $45.9 \%$ seroprevalence was detected in stray cats from Emilia-Romagna [18]. Values ranging between $16 \%$ and $34 \%$ were found in cats in Central Italy $[19,20]$. Finally, prevalences of $54.8 \%, 45.7 \%$ and $47.3 \%$ were detected in cats from Southern Italy [21-23]. Furthermore, Pinna Parpaglia et al. [24] found $22 \%$ of cats were positive in Sardinia, whereas Zobba et al. [25] found a $11 \%$ seroprevalence, with $6 / 55$ cats positive, in the same region.

All cats tested in this survey were infested by $C$. felis, which is known as the main vector of $B$. henselae. Our findings confirm that cats parasitized by $C$. felis are often infected by $B$. henselae, suggesting that owners of these animals have a high possibility to contract this agent.

C. felis is also involved in the epidemiology of R. felis. This is an emerging zoonotic pathogen that has been found in Italy, as shown by a molecular study carried out in fleas collected in Sicily (Southern Italy) that found R. felis DNA in $25.76 \%$ of C. felis analyzed [26].

Serological studies about the prevalences of cats positive to $R$. felis and/or R. conorii in Italy are not numerous; thus it is difficult to compare our results with the Italian epidemiological status. Morganti et al. [27] found $8.04 \%$ and $6.29 \%$ of cats positive for $R$. felis and $R$. conorii, respectively, with low titers (1:64-1:128), whereas values of $2.4 \%$ for $R$. felis and $54.8 \%$ for $R$. conorii were observed in a small number of cats in Southern Italy [21]. A $10.8 \%$ seroprevalence of domestic cats positive to $R$. felis was detected in Central-Southern Italy [28].

In our investigation, a prevalence of $17.89 \%$ for $R$. felis was detected when cats with antibody titers $>1: 32$ were considered as positive; considering the titer 1:64 as cutoff, the seroprevalence was $10.52 \%$, which is more similar to the values found by both Morganti et al. [27] and Morelli et al. [28]. Furthermore, antibody titers not $>1: 128$ were observed in our investigation, too.

Conversely, our results are not in agreement with the previous study in Southern Italy that found $54.8 \%$ of $R$. conorii-positive cats. In fact, the present survey detected $14.73 \%$ of cats positive to this agent with antibody titers $>1: 32$, but only $3.15 \%$ with $1: 64$ titers. This low prevalence could be related to scarce occasions for the tested cats to contract $R$. conorii, which is usually transmitted by ticks, mainly $R$. sanguineus. In fact, the presence of ticks on cats is not frequent due to their grooming habits. However, $R$. conorii has been detected in C. felis, too [29], thus it cannot be excluded that cats infested by fleas can contract this SFG Rickettsia.

Four animals were positive to both R. conorii and R. felis; these results could be related to coinfections by the two agents or to cross-reactions that are possible between SFG rickettsias. In fact, IFA is usually employed in the serological diagnosis of rickettsiosis, being considered the gold standard method, but it cannot always discriminate infections caused by different Rickettsia spp. [30].

No R. typhi-positive cats were detected according to a previous investigation that did not find seropositive cats in Spain [31]. Conversely, $15.8 \%$ seroprevalence in naturally infected cats was found in a study carried out in Northeast Spain; moreover, in the same investigation, five seropositive cats and $55 \%$ of $C$. felis analyzed were PCR-positive for R. typhi [32].

In recent years, several cases of human $R$. typhi infection have been reported in the Mediterranean area [33]. In Italy, murine typhus was the most widespread rickettsiosis 
during World War II, mainly in Sicily, from where other cases were reported in the late 1980s. A case of murine typhus was observed in an older woman from Calabria (South Italy) in 2013 [34]. To the best of our knowledge, only one serological study investigated the occurrence of anti-R. typhi antibodies in cats in Italy: Morelli and coworkers [28] found 4.2\% positivity in domestic cats living in some areas of Central and Southern Italy. However, all $R$. typhi-positive cats had antibodies to R. felis, too; thus the findings could be due to a multiple infection with these two pathogens but also to cross-reactions.

The cases of $R$. typhi infection in human beings and the epidemiological situation in the Mediterranean countries suggest the need to monitor feline populations and their fleas for this emerging rickettsia, as well as other arthropod-borne pathogens. Climate change in recent decades has favored increasing rates of hematophagous arthropods, including fleas, which may transmit several pathogens.

Two out of 95 examined cats (2.1\%) scored positive for N. caninum with a low antibody titer. In the present report, IFA was employed, being considered as the gold standard for diagnostic purposes in many animal species [35]. However, most epidemiological studies have been carried out on bovine and canine sera.

Data about seroprevalence in cats are quite variable, so our data can be compared with the results obtained elsewhere. Even though clinical cases of feline neosporosis in naturally infected cats have not been reported, the health status of tested populations could affect seroprevalence rates, with a broad range of seropositivity. To the best of our knowledge, only five serologic studies have been carried out in Europe. Ferroglio et al. [36] found $24.8 \%$ of cats from Turin were positive, with very high antibody titers; otherwise, the seroprevalences reported by other authors would agree with our data. A serologic survey in Hungary reported $0.6 \%$ of cats positive [15]; seroprevalence of $3.86 \%$ in the Czech Republic has been thereafter found [37], as well as $0.7 \%$ in Albania [14] and 6.8\% in Majorca [38]. The first report of occurrence of N. caninum antibodies in cats (11.9\%) was from Brazil [39], then other studies have followed, with seroprevalences of $0 \%$ [40], $2.9 \%$ [41], 24.5\% [42] and 37\% [43]. Other reports from Thailand and Iran refer to $0 \%$ [44] and $14-19 \%$ [45], respectively. These striking differences among the studies would probably depend on the presence of final hosts in the environment, too. Dogs are responsible for the infection of rodents, which are common prey of cats living outdoors. This hypothesis is corroborated by the results of serological studies carried out in Tuscany on autochthonous wildlife mammals; they showed seroprevalences of $28 \%$ in red deer [46] and $1.3 \%$ in hares [47], from areas where several dogs were living and in protected areas not attended by them, respectively.

The rate of seroprevalence versus T. gondii (14.73\%) appears quite low in comparison with a previous study in colony cats from Tuscany, showing $44 \%$ prevalence [48]. However, serological data of cats from Europe yielded percentages of seropositivity ranging from $10 \%$ in Persian cats from Spain [49] to 82\% in domestic cats from Poland [50]. Furthermore, the data from the present study agree with the seroprevalence values of toxoplasma infection of cats from Italy, ranging from $0.4 \%$ [51] to $50.4 \%$ [52]. It is well known that the prevalence of toxoplasma infection appears to widely vary depending on the age of host, the lifestyle and the availability of food [6]. So, the present data, coupled with the low occurrence of antibodies against $N$. caninum, would suggest that the selected cats (mostly young) although living outdoors, were not used to feeding on their prey.

\section{Conclusions}

Cats are frequently infected by pathogens, most of which are zoonotic. Emerging microorganisms, such as Rickettsia spp., seem to circulate among feline populations through fleas and/or ticks acting as vectors. For these reasons, cats, mainly pets, should be periodically monitored to verify possible infections due not only to well-known pathogens such as B. henselae and T. gondii, but also to emerging microorganisms. Moreover, careful controls against hematophagous arthropods on cats and in domestic environments are necessary to reduce the chance of infection for cats' owners. 
Author Contributions: Conceptualization, V.V.E. and F.M.; methodology, V.V.E., S.N., M.M., S.P. and F.M.; data curation, V.V.E., S.N. and F.M.; writing-original draft preparation, V.V.E. and F.M.; writing-review and editing, V.V.E. and F.M. All authors have read and agreed to the published version of the manuscript.

Funding: This research received no external funding.

Institutional Review Board Statement: Ethical review and approval were waived for this study, because no samples were collected from animals exclusively for this study. All samples were previously collected by veterinarians for diagnostic purposes.

Informed Consent Statement: Not applicable.

Data Availability Statement: Data are contained within the article.

Conflicts of Interest: The authors declare no conflict of interest.

\section{References}

1. Chomel, B.B.; Boulouis, H.J.; Breitshwerdt, E.B.; Kasten, R.W.; Vayssier-Taussat, M.; Birtles, R.J.; Koehler, J.E.; Dehio, C. Ecological fitness and strategies of adaptation of Bartonella species to their hosts and vectors. Vet. Res. 2009, 40, 29. [CrossRef]

2. Chomel, B.B. Cat-scratch disease. Rev. Sci. Tech. 2000, 19, 136-150. [CrossRef]

3. Djurković-Djaković, O.; Dupouy-Camet, J.; Van der Giessen, J.; Dubey, J.P. Toxoplasmosis: Overview from a One Health perspective. Food Waterborne Parasitol. 2019, 15, e00054. [CrossRef]

4. Stokkermans, T.J.; Havens, S.J. Toxoplasma Retinochoroiditis. In StatPearls [Internet]; StatPearls Publishing: Treasure Island, FL, USA, 2020.

5. Lindsay, D.S.; Dubey, J.P. Neosporosis, Toxoplasmosis, and Sarcocystosis in Ruminants: An Update. Vet. Clin. N. Am. Food Anim. Pract. 2020, 36, 205-222. [CrossRef]

6. Dubey, J.P.; Cerqueira-Cézar, C.K.; Murata, F.H.A.; Kwok, O.C.H.; Yang, Y.R.; Su, C. All about toxoplasmosis in cats: The last decade. Vet. Parasitol. 2020, 283, 109145. [CrossRef]

7. Portillo, A.; Santibáñez, S.; García-Álvarez, L.; Palomar, A.M.; Oteo, J.A. Rickettsioses in Europe. Microbes Infect. 2015, 17, 834-838. [CrossRef]

8. Brouqui, P.; Parola, P.; Fournier, P.E. Spotted fever rickettsioses in southern and eastern Europe. FEMS Immunol. Med. Microbiol. 2007, 49, 2-12. [CrossRef]

9. Wedincamp, J.; Foil, L.D. Vertical transmission of Rickettsia felis in the cat flea (Ctenocephalides felis Bouché). J. Vector Ecol. 2002, 27, 96-101.

10. Hun, L.; Troyo, A. An update on the detection and treatment of Rickettsia felis. Res. Rep. Trop. Med. 2012, 3, 47-55. [CrossRef]

11. Maurin, M.; Raoult, D. Rickettsia typhi (Murine Typhus). Available online: www.antimicrobe.org/r06.asp (accessed on 27 May 2021).

12. Dubey, J.P.; Lindsay, D.S. Fatal Neospora caninum infection in kittens. J. Parasitol. 1989, 75, 148-151. [CrossRef]

13. Dubey, J.P.; Lindsay, D.S. A review of Neospora caninum and neosporosis. Vet. Parasitol. 1996, 67, 1-59. [CrossRef]

14. Silaghi, C.; Knaus, M.; Rapti, D.; Kusi, I.; Shukullari, E.; Hamel, D.; Pfister, K.; Rehbein, S. Survey of Toxoplasma gondii and Neospora caninum, haemotropic mycoplasmas and other arthropod-borne pathogens in cats from Albania. Parasites Vectors 2014, 7, 62. [CrossRef]

15. Hornok, S.; Edelhofer, R.; Joachim, A.; Farkas, R.; Berta, K.; Répási, A.; Lakatos, B. Seroprevalence of Toxoplasma gondii and Neospora caninum infection of cats in Hungary. Acta Vet. Hung. 2008, 56, 81-88. [CrossRef] [PubMed]

16. Fabbi, M.; Vicari, N.; Tranquillo, M.; Pozzi, C.; Prati, P.; De Meneghi, D.; Bertoletti, I.; Lauzi, S.; Guiso, P.; Genchi, C. Prevalence of Bartonella henselae in stray and domestic cats in different Italian areas: Evaluation of the potential risk of transmission of Bartonella to humans. Parassitologia 2004, 46, 127-129.

17. Brunetti, E.; Fabbi, M.; Ferraioli, G.; Prati, P.; Filice, C.; Sassera, D.; Dalla Valle, C.; Bandi, C.; Vicari, N.; Marone, P. Cat-scratch disease in Northern Italy: Atypical clinical manifestations in humans and prevalence of Bartonella infection in cats. Eur. J. Clin. Microbiol. Infect. Dis. 2013, 32, 531-534. [CrossRef]

18. Ebani, V.V.; Guardone, L.; Marra, F.; Altomonte, I.; Nardoni, S.; Mancianti, F. Arthropod-Borne Pathogens in Stray Cats from Northern Italy: A Serological and Molecular Survey. Animals 2020, 10, 2334. [CrossRef]

19. Ebani, V.V.; Cerri, D.; Andreani, E. Cat scratch disease. Survey on the presence of Bartonella henselae among cats of Tuscany. New Microbiol. 2002, 25, 307-313.

20. Ebani, V.V.; Bertelloni, F.; Fratini, F. Occurrence of Bartonella henselae types I and II in Central Italian domestic cats. Res. Vet. Sci. 2012, 93, 63-66. [CrossRef]

21. Persichetti, M.F.; Solano-Gallego, L.; Serrano, L.; Altet, L.; Reale, S.; Masucci, M.; Pennisi, M.G. Detection of vector-borne pathogens in cats and their ectoparasites in southern Italy. Parasites Vectors 2016, 9, 247. [CrossRef]

22. Persichetti, M.F.; Pennisi, M.G.; Vullo, A.; Masucci, M.; Migliazzo, A.; Solano-Gallego, L. Clinical evaluation of outdoor cats exposed to ectoparasites and associated risk for vector-borne infections in southern Italy. Parasites Vectors 2018, 11, 136. [CrossRef] 
23. Grippi, F.; Galluzzo, P.; Guercio, A.; Blanda, V.; Santangelo, F.; Sciortino, S.; Vicari, D.; Arcuri, F.; Di Bella, S.; Torina, A. Serological and Molecular Evidence of Bartonella henselae in Stray Cats from Southern Italy. Microorganisms 2021, 9, 979. [CrossRef]

24. Pinna Parpaglia, M.L.; Masu, G.; Masala, G.; Porcu, R.; Zobba, R.; Pintori, G.; Cocco, R. Seroprevalence of Bartonella henselae in dogs and cats in Sassari. Vet. Res. Commun. 2007, 31 (Suppl. S1), 317-320. [CrossRef] [PubMed]

25. Zobba, R.; Chessa, G.; Mastrandrea, S.; Pinna Parpaglia, M.L.; Patta, C.; Masala, G. Serological and molecular detection of Bartonella spp. in humans, cats and dogs from northern Sardinia, Italy. Clin. Microbiol. Infect. 2009, 15 (Suppl. S2), $134-135$. [CrossRef] [PubMed]

26. Giudice, E.; Di Pietro, S.; Alaimo, A.; Blanda, V.; Lelli, R.; Francaviglia, F.; Caracappa, S.; Torina, A. A molecular survey of Rickettsia felis in fleas from cats and dogs in Sicily (Southern Italy). PLoS ONE 2014, 9, e106820. [CrossRef]

27. Morganti, G.; Veronesi, F.; Stefanetti, V.; Di Muccio, T.; Fiorentino, E.; Diaferia, M.; Santoro, A.; Passamonti, F.; Gramiccia, M. Emerging feline vector-borne pathogens in Italy. Parasites Vectors 2019, 12, 193. [CrossRef]

28. Morelli, S.; Crisi, P.E.; Di Cesare, A.; De Santis, F.; Barlaam, A.; Santoprete, G.; Parrinello, C.; Palermo, S.; Mancini, P.; Traversa, D. Exposure of client-owned cats to zoonotic vector-borne pathogens: Clinic-pathological alterations and infection risk analysis. Comp. Immunol. Microbiol. Infect. Dis. 2019, 66, 101344. [CrossRef]

29. Khrouf, F.; M'Ghirbi, Y.; Znazen, A.; Jemaa, M.B.; Hammami, A.; Bouattour, A. Detection of Rickettsia in Rhipicephalus sanguineus ticks and Ctenocephalides felis fleas from southeastern Tunisia by reverse line blot assay. J. Clin. Microbiol. 2014, 52, 268-274. [CrossRef]

30. La Scola, B.; Raoult, D. Laboratory diagnosis of rickettsioses: Current approaches to diagnosis of old and new rickettsial diseases. J. Clin. Microbiol. 1997, 35, 2715-2727. [CrossRef]

31. Gracia, M.J.; Marcén, J.M.; Pinal, R.; Calvete, C.; Rodes, D. Prevalence of Rickettsia and Bartonella species in Spanish cats and their fleas. J. Vector Ecol. 2015, 40, 233-239. [CrossRef]

32. Nogueras, M.M.; Pons, I.; Ortuño, A.; Miret, J.; Pla, J.; Castellà, J.; Segura, F. Molecular detection of Rickettsia typhi in cats and fleas. PLoS ONE 2013, 8, e71386. [CrossRef]

33. Dougas, G.; Mavrouli, M.; Tsakris, A.; Billinis, C.; Papaparaskevas, J. Serosurvey of IgG Antibodies against Bartonella henselae and Rickettsia typhi in the Population of Attica, Greece. Trop. Med. Infect. Dis. 2020, 5, 145. [CrossRef]

34. Luciani, F.; Cione, E.; Corsonello, A.; Guido, F.; De Santis, S.; Cannataro, R.; Perri, M.; Caroleo, M.C.; Cannataro, A.M. Spotted fever from Rickettsia typhi in an older woman: A case report from a geographic area where it would not be expected. Int. J. Infect. Dis. 2014, 27, 10-12. [CrossRef] [PubMed]

35. Dubey, J.P. Review of Neospora caninum and neosporosis in animals. Korean J. Parasitol. 2003, 41, 1-16. [CrossRef]

36. Ferroglio, E.; Guiso, P.; Pasino, M.; Accossato, A.; Trisciuoglio, A. Antibodies to Neospora caninum in stray cats from north Italy. Vet. Parasitol. 2005, 131, 31-34. [CrossRef] [PubMed]

37. Sedlák, K.; Bartova, E.; Machacova, T. Seroprevalence of Neospora caninum in cats from the Czech Republic. Acta Parasitol. 2014, 59, 359-361. [CrossRef]

38. Millán, J.; Cabezón, O.; Pabón, M.; Dubey, J.P.; Almería, S. Seroprevalence of Toxoplasma gondii and Neospora caninum in feral cats (Felis silvestris catus) in Majorca, Balearic Islands, Spain. Vet. Parasitol. 2009, 165, 323-326. [CrossRef] [PubMed]

39. Dubey, J.P.; Lindsay, D.S.; Hill, D.; Romand, S.; Thulliez, P.; Kwok, O.C.; Silva, J.C.; Oliveira-Camargo, M.C.; Gennari, S.M. Prevalence of antibodies to Neospora caninum and Sarcocystis neurona in sera of domestic cats from Brazil. J. Parasitol. 2002, 88, 1251-1252. [CrossRef]

40. Dourado Coelho, W.M.; Amarante, A.F.S.; de Carvalho Apolinário, J.; Dourado Coelho, N.M.; de Lima, V.M.F.; Perri, S.H.V.; Bresciani, K.D.S. Seroepidemiology of Toxoplasma gondii, Neospora caninum, and Leishmania spp. Infections and risk factors for cats from Brazil. Parasitol. Res. 2011, 109, 1009-1013. [CrossRef] [PubMed]

41. Sousa, K.C.; Herrera, H.M.; Domingos, I.H.; Campos, J.B.; Santos, I.M.; Neves, H.H.; Machado, R.Z.; André, M.R. Serological detection of Toxoplasma gondii, Leishmania infantum and Neospora caninum in cats from an area endemic for leishmaniasis in Brazil. Rev. Bras. Parasitol. Vet. 2014, 23, 449-455. [CrossRef]

42. Bresciani, K.D.S.; Gennai, S.M.; Serrano, A.C.M.; Rodrigues, A.A.R.; Ueno, T.; Franco, L.G.; Perri, S.H.V.; Amarante, A.F.T Antibodies to Neospora caninum and Toxoplasma gondii in domestic cats from Brazil. Parasitol. Res. 2007, 100, 281-285. [CrossRef]

43. Munhoz, A.D.; Hage, S.B.; Cruz, R.D.S.; Calazans, A.P.F.; Silva, F.L.; Albuquerque, G.R.; Lacerda, L.C. Toxoplasmosis in cats in northeastern Brazil: Frequency, associated factors and coinfection with Neospora caninum, feline immunodeficiency virus and feline leukemia virus. Vet. Parasitol. Reg. Stud. Rep. 2017, 8, 35-38. [CrossRef] [PubMed]

44. Arunvipas, P.; Inpankaew, T.; Jittapalapong, S. Risk factors of Neospora caninum infection in dogs and cats in dairy farms in Western Thailand. Trop. Anim. Health Prod. 2012, 44, 1117-1121. [CrossRef] [PubMed]

45. Gharekhani, J.; Yakhchali, M.; Berahmat, R. Neospora caninum infection in Iran (2004-2020): A review. J. Parasit. Dis. 2020, 44, 1-16. [CrossRef]

46. Rocchigiani, G.; Nardoni, S.; D’Ascenzi, C.; Nicoloso, S.; Picciolli, F.; Papini, R.A.; Mancianti, F. Seroprevalence of Toxoplasma gondii and Neospora caninum in red deer from Central Italy. Ann. Agric. Environ. Med. 2016, 23, 699-701. [CrossRef]

47. Ebani, V.V.; Poli, A.; Rocchigiani, G.; Bertelloni, F.; Nardoni, S.; Papini, R.A.; Mancianti, F. Serological survey on some pathogens in wild brown hares (Lepus europaeus) in Central Italy. Asian Pac. J. Trop. Med. 2016, 9, 465-469. [CrossRef]

48. Mancianti, F.; Nardoni, S.; Ariti, G.; Parlanti, D.; Giuliani, G.; Papini, R.A. Cross-sectional survey of Toxoplasma gondii infection in colony cats from urban Florence (Italy). J. Feline Med. Surg. 2010, 12, 351-354. [CrossRef] 
49. Miró, G.; Hernández, L.; Montoya, A.; Arranz-Solís, D.; Dado, D.; Rojo-Montejo, S.; Mendoza-Ibarra, J.A.; Ortega-Mora, L.M.; Pedraza-Díaz, S. First description of naturally acquired Tritrichomonas foetus infection in a Persian cattery in Spain. Parasitol. Res. 2011, 109, 1151-1154. [CrossRef]

50. Michalski, M.; Platt-Samoraj, A.; Mikulska-Skupień, E. Toxoplasma gondii antibodies in domestic cats in Olsztyn urban area, Poland. Wiad. Parazytol. 2010, 56, 277-279.

51. Macrì, G.; Masotti, G.F.; Scholl, F.; Faini, A.; Villini, E. Feline Toxoplasmosis: Sieropositivity in a sample of domestic and wild cats. Atti. S.I.S. Vet. 1992, 46, 1413-1417.

52. Cavallini, F. Prevalence of toxoplasmosis among domestic and wild animals in the area of Siena, Italy. Am. J. Trop. Med. Hyg. 1969, 18, 391-394. 